\title{
HISTÓRIA, EDUCAÇÃO AMBIENTAL E POLÍTICAS: UMA RETROSPECTIVA DA REALIDADE BRASILEIRA E UMA ABORDAGEM SOBRE OS SEUS DESAFIOS ${ }^{1}$
}

\author{
Ivonaldo Leite \\ Universidade Federal da Paraíba (UFPB)
}

\section{RESUMO}

O presente artigo resulta de uma pesquisa recentemente concluída e tem como objetivo geral realizar uma abordagem das políticas brasileiras de educação ambiental, enfocandoas numa retrospectiva histórica. Do ponto de vista metodológico, tem um duplo suporte: um de natureza lógico-analítica, partindo do pressuposto que o sentido da história, em dado contexto, condiciona o sentido da educação; e outro de caráter empírico, na medida em que o trabalho é construído a partir da incursão em fontes primárias, quais sejam, os documentos das políticas educacionais. Dentre os resultados obtidos, podem ser referidos, entre outros, os seguintes: 1) as políticas brasileiras voltadas ao meio ambiente buscaram superar a percepção meramente naturalista do mesmo; 2) as iniciativas governamentais no país em torno da educação ambiental têm sido historicamente condicionadas por orientações externas, de organizações internacionais como a UNESCO; 3) da segunda metade da década de 1990 aos dias atuais, no básico, há uma espécie de continuidade das políticas de educação ambiental, apesar de comando partidário ocorrida no país em 2002; 4) nos anos 2000, as ações governamentais em função do meio ambiente e da educação ambiental foram marcadas por um grau de ambivalência decorrente, este, em parte, da perspectiva econômica do chamado neodesenvolvimentismo. Conclusivamente, é assinalado, por exemplo, que, em decorrência das particularidades que têm marcado o debate sobre meio ambiente e as políticas de educação ambiental no Brasil, a noção de desenvolvimento sustentável tem se constituído numa expressão vazia, genérica, repetida por diferentes segmentos, mas sem clarificação consistente do que significa em termos de conteúdo, e assim assume uma dimensão propensa à manipulação político-ideológica. Palavras-chave: Educação ambiental; história; políticas; desenvolvimento sustentável.

\section{HISTORY, ENVIRONMENTAL EDUCATION AND POLICIES: A RETROSPECTIVE OF THE BRAZILIAN REALITY AND AN APPROACH ABOUT ITS CHALLENGES}

\begin{abstract}
This paper results of a research which was recently concluded. It has as general objective to make an analysis of the Brazilian environmental educational policies by a historical perspective. Methodologically, it has a double background. The first one is analytic logic and affirms that the historical perspective, by each specific context, influences the decisions about the kind of educational proposals. The second one has an empirical character, since it represents the documents of the Brazilian environmental educational policies which were analysed. As outcomes, it found out the following facts: 1) the Brazilian environmental policies tried to overcome the naturalist conception about environment; 2) the official initiatives in Brazil on the environmental education have been historically influenced by international orientations of organization like UNESCO; 3) from second half of 1990s until nowadays, there is a continuity of the Brazilian environmental educational policies, although in 2002 it has happened a change of political parties in Brazilian government; 4) During the 2000s decade, the Brazilian policies to
\end{abstract}


environment and environmental education were characterized by an ambivalence level which is consequence, somehow, of the economic perspective formulated by so-called new-developementalism. Conclusively, it is affirmed, for instance, that the sustainable development concept in Brazil has been utilized in generic way. This means without specific content. Nevertheless it is repeated by several segments. Hence, the sustainable development concept has been utilized in Brazilian context as a channel of ideological manipulation.

Keywords: Environmental education; history; policies; sustainable development.

\section{Introdução}

O significado do fenômeno educativo encontra-se estreitamente relacionado com o significado da história, tendo-se que, no âmbito da pesquisa histórico-educativa, essa relação é duplamente reforçada. Isto é, "do ponto de vista do objeto, em razão da determinação histórica que se exerce sobre o fenômeno educativo; e do ponto de vista do enfoque, dado que pesquisar em história da educação é investigar o objeto educação sob a perspectiva histórica" (SAVIANI, 1998, p. 12).

Partindo desse pressuposto, é de se ter em consideração que, apesar das tendências partidárias da fragmentação histórica e até mesmo não obstante os eventuais contributos que elas aportem, o enfoque histórico em educação não pode perder de vista o longo alcance, ou seja, as abordagens que busquem a compreensão global dos fatos. Não há razão, então, para se renunciar às perspectivas que procuram enfocá-los em uma temporalidade estendida, pois esta é uma condição sine qua non para captar a geneologia dos acontecimentos.

O presente trabalho, portanto, pauta-se por essa orientação teórico-metodológica. Procura tratar da temática das políticas de educação ambiental no Brasil tendo como referência o longo alcance histórico, bem como valorizando um enfoque que busca captar os macrofatores que condicionam a referida temática e as iniciativas desenvolvidas a seu respeito.

\section{Panorama histórico das políticas brasileiras de educação ambiental}

No Brasil, como provavelmente também em outros países, a discussão sobre Educação Ambiental (EA) precedeu à sua institucionalização. Já na década de 1970, verificava-se no país a existência de um movimento ambientalista que, em face da ditadura militar, buscava articular as suas ações com as manifestações em defesa das liberdades democráticas, chamando a atenção para o imperativo da preservação ambiental.

A institucionalização de iniciativas contemplando a educação ambiental emerge em 1973 com a criação da Secretaria Especial do Meio Ambiente (SEMA) ${ }^{2}$, vinculada ao então Ministério do Interior. Na década seguinte, em 1981, mediante a Lei 9.398/813 instituiu-se a Política Nacional de Meio Ambiente (PNMA), que, em seu artigo $2^{\circ}$, inciso $\mathrm{X}$, assinala a necessidade da educação ambiental a todos os níveis de ensino, inclusive a educação da comunidade, objetivando capacitá-la para participação ativa na defesa do meio ambiente (BRASIL, 1981). Com a constituição de 1988, no artigo 225, inciso VI, é estabelecido que se deve promover a educação ambiental em todos os níveis de ensino, 
assim como a conscientização pública para a preservação do meio ambiente (BRASIL, 1988).

Em 1989, foi criado o Instituto Brasileiro do Meio Ambiente (IBAMA) ${ }^{4}$, e em 1991, por ocasião da Conferência Rio ECO 92, a Comissão Interministerial que tratava da sua preparação considerou a EA como um dos principais instrumentos da política ambiental brasileira. Dessa maneira, foram instituídas duas instâncias no âmbito do Poder Executivo com o propósito de tratar especificamente da mesma, quais sejam: o Grupo de Trabalho de Educação Ambiental do MEC, que em 1993 se transformou na Coordenação Geral de Educação Ambiental (COEA/MEC), e a Divisão de Educação Ambiental do IBAMA, cujas competências institucionais foram definidas no sentido de representar um marco para a institucionalização da política de Educação Ambiental na esfera do Sistema Nacional de Meio Ambiente (SISNAMA). Em 1994, foi criado o Ministério do Meio Ambiente (MMA).

Buscando-se criar instâncias de referência para a elaboração dos programas estaduais e municipais de EA, o IBAMA e o Ministério do Meio Ambiente estimularam a constituição das Comissões Interinstitucionais Estaduais de Educação Ambiental. Em 1994, como resultado dos compromissos assumidos pelo Brasil durante a ECO 92, a Presidência da República criou o Programa Nacional de Educação Ambiental (PRONEA), compartilhado pelo Ministério do Meio Ambiente, Ministério da Educação, Ministério da Cultura e Ministério da Ciência e Tecnologia. Em 1997, após várias discussões, foram aprovados os Parâmetros Curriculares Nacionais (PCNs), aportando subsídios para apoiar as escolas na elaboração dos projetos pedagógicos, e inserindo temas urgentes da realidade contemporânea para serem discutidos como temas transversais nas disciplinas, estando presente aí o tema ambiental.

Fechando esse ciclo de configuração do quadro das atuais políticas brasileiras de educação ambiental, deve-se referir, por fim, três dispositivos institucionais: 1) a Lei $\mathrm{n}^{\circ}$ 9.795/99, que dispõe sobre a Política Nacional de Educação Ambiental, aprovada em 1999; 2) o Decreto $n^{\circ} 4.281 / 02$, aprovado em 2002, regulamentando a Lei $n^{\circ} 9.795 / 99$; 3) a revisão, em 2004, do Programa Nacional de Educação Ambiental (PRONEA), realizada mediante um processo de consulta pública, em parceria com as Comissões Interinstitucionais Estaduais de Educação Ambiental (CIEAs) e as Redes de Educação Ambiental, envolvendo cerca de 800 educadores ambientais dos estados (BRASIL, 2004).

Essa é a trajetória do quadro institucional das políticas brasileiras de educação ambiental, cujo impulso de maior estruturação ocorre entre os anos 1990 e a primeira década do século XXI. É de se realçar que, muito embora nesse período tenha ocorrido uma suposta mudança ideológica na chefia do executivo federal (com a troca do governo do PSDB pelo do PT), não foram verificadas alterações substanciais no percurso de estruturação dos marcos gerais das políticas de educação ambiental. Os marcos que vinham sendo delineados desde os anos 1990 seguiram o seu curso, passando apenas por pequenas revisões e/ou adaptações.

\section{Percursos e perspectivas das propostas de formação de educadores ambientais}

O tema formação em educação ambiental tem sido apresentado, oficialmente, como um 'eixo estratégico' das ações nesse contexto, em observância ao que estabelece a Lei 9.795/99, conforme atestavam, em 2002, as próprias palavras da Coordenadora de Educação Ambiental da Secretaria de Ensino Fundamental do MEC' : "O tema 'Formação em Educação Ambiental' é o eixo estratégico das propostas de implementação de 
processos de Educação Ambiental, contemplado no art. $8^{\circ}$ da Lei $n^{\circ}$ 9.795/99, que trata da Política Nacional de Educação Ambiental" (VIANNA, 2002, p. 72).

Ao termos em atenção o artigo $8^{\circ}$ da referida Lei, no que concerne especificamente à preparação dos agentes formadores de EA, observamos que ele estabelece que a capacitação de recursos humanos voltar-se-á para:

- A incorporação da dimensão ambiental na formação, especialização e atualização dos educadores de todos os níveis e modalidades de ensino;

- A incorporação da dimensão ambiental na formação, especialização e atualização dos profissionais de todas as áreas;

- A preparação de profissionais orientados para as atividades de gestão ambiental;

- A formação, especialização e atualização de profissionais na área de meio ambiente;

- O atendimento da demanda dos diversos segmentos da sociedade no que diz respeito à problemática ambiental.

A partir disso, tem-se em perspectiva tanto a formação inicial de educadores como a formação em serviço, com vistas ao trabalho pedagógico em EA. Neste sentido, o PRONEA (2004) apresenta as seguintes diretrizes para a formação de educadores ambientais:

- Formação continuada de educadores e gestores ambientais, no âmbito formal e não formal;

- Construção de planos de formação continuada a serem implementados a partir de parcerias com universidades, escolas, empresas e entidades da sociedade civil em geral;

- Oferta de suporte à qualificação de quadros profissionais das gerências, agências e departamentos de EA, assim como a adequação tecnológica dos mesmos;

- Realização de parcerias entre escolas públicas e universidades, tornando mais acessível o acesso dos professores da rede pública de ensino básico aos cursos de pós-graduação lato sensu e stricto sensu em EA;

- Institucionalização de programas de formação em EA voltados aos profissionais da educação especial, abordando a importância da inclusão de pessoas com necessidades especiais na capacitação dos educadores ambientais em geral;

- Criação de redes de formação de educadores com a participação de universidades, escolas, empresas e organizações do terceiro setor;

- Formação continuada de docentes e técnicos, desde a educação pré-escolar ao ensino superior, utilizando-se metodologias presenciais e de educação a distância;

- Implementação de metodologias de educação a distância mediante o uso de novas tecnologias da informação e comunicação, como videoconferências, teleaulas, e-learning, entre outras.

Além das diretrizes da PNEA e do PRONEA, alguns eventos têm sido realizados para definir subsídios à formação de educadores ambientais, procurando-se, talvez, atingir maior concreticidade e objetividade na delimitação dos aportes para a formação de educadores ambientais. Nesse sentido, somos informados pela Coordenação de Educação Ambiental (COEA), do MEC, que ela: "a fim de subsidiar sua proposta de trabalho e de promover um espaço de participação e articulação da Educação Ambiental, promoveu a Oficina Panorama da Educação Ambiental, para a qual convidou 17 especialistas de organizações não governamentais e universidades" (VIANNA, 2002, p. 74). Disso decorreu que,"a partir das discussões dos grupos de trabalho e das plenárias, foram traçados alguns pontos comuns sobre a prática da formação de professores” (IBIDEM, p. 74), e foram apontadas orientações para propostas de formação de educadores. São elas: 


\begin{abstract}
Desenvolvimento da competência e capacidade de mudança, risco e investigação; comprometimento com a aprendizagem contínua; fortalecimento da autonomia do professor para sua própria formação; desenvolvimento da competência de trabalhar e aprender em equipes cooperativas; incentivar a aprendizagem profissional com seus colegas; viabilizar a capacidade dos professores para formar pessoas conscientes, solidárias e capazes de aprender. (IBIDEM, p. 74).
\end{abstract}

Ainda no âmbito da COEA, mais especificamente na esfera da Secretaria de Educação Fundamental, elaborou-se a proposta de formação em EA para professores em serviço. Denomina-se 'Parâmetros em Ação - Meio Ambiente na Escola', sendo adotado em parceria com os sistemas de ensino. Tem como pressuposto as seguintes premissas (IBIDEM):

- A importância de a formação de professores em serviço ser contínua, evitando ações fragmentadas e pulverizadas, garantindo melhoria da qualidade do ensino;

- O entendimento de que o universo escolar, como espaço - reconhecido pela sociedade de aprendizagem planejada e sistemática, é privilegiado para a vivência, a reflexão e a discussão de referenciais éticos necessários e constituidores de toda e qualquer ação de cidadania;

- A consciência de que não promove a aprendizagem quem não a domina, nem constrói conhecimentos significativos quem não os possui, nem promove autonomia quem não teve a oportunidade de construí-la;

- A importância do desenvolvimento de competências profissionais para a prática docente o Programa elegeu quatro competências profissionais básicas: leitura e escrita; trabalho compartilhado; administração da própria formação; reflexão da prática pedagógica.

Tendo como referência essas premissas, o Programa 'Parâmetros em Ação - Meio Ambiente na Escola' tem como os seus principais objetivos: incentivar a prática de formação continuada no interior dos sistemas educacionais; fortalecer o papel das secretarias na formação dos professores, evitando a fragmentação e a pulverização das ações educacionais; favorecer a continuidade das ações de formação, incentivando o estabelecimento de organização de trabalho e de equipe de formadores nas secretarias de educação; contribuir para o debate e a reflexão sobre o papel da escola e do professor na perspectiva do desenvolvimento de uma prática de transformação da ação pedagógica; criar espaços de aprendizagem coletiva, incentivando a prática de encontros para estudar, trocar experiências e realizar trabalho coletivo nas escolas; colocar à disposição dos sistemas de ensino, de forma organizada, os conteúdos e as metodologias de formação.

Programa pensado para os professores das séries finais do Ensino Fundamental, em parceria com as secretarias de educação, ele é destinado a todos os docentes, e não somente, por exemplo, aos de áreas mais relacionadas à temática ambiental, como os de ciências e geografia. Tem os seus propósitos gerais disseminados por uma diversidade de objetivos específicos, tais como:

- Institucionalizar a Educação Ambiental nas políticas de formação continuada em serviço das secretarias de educação;

- Fortalecer os sistemas de ensino para o trabalho com Educação Ambiental;

- Propiciar a superação de visões parciais e especializadas do mundo;

- Incentivar a adoção de valores éticos e solidários que sirvam de base às relações sociais e às relações com a natureza; 
- Estimular o repensar do espaço, o convívio escolar e a reflexão sobre o ambiente onde a escola se situa;

- Estimular ações de intervenção por meio de construção de projetos;

- Incentivar o domínio de conhecimentos básicos, que criem condições de apropriação do repertório mínimo acerca das questões ambientais.

As propostas das políticas aqui realçadas para a formação de educadores ambientais constituem uma amostra fundamental do que, nos últimos anos, foi pensado para a área. Da apreciação dessas propostas, contudo, é possível inferir aspectos abstrusos perpassando-as, conforme pretendemos evidenciar a seguir.

Sem prejuízo de uma análise crítica das propostas das políticas brasileiras de educação ambiental para a formação de educadores ambientais, é de se assinalar algumas pertinências dessas políticas na área. Destacamos quatro.

A primeira pertinência diz respeito ao esforço para superar a visão meramente naturalista da questão ambiental, concebendo-a na perspectiva do socioambientalismo. Daí resulta que o ser humano e a natureza são concebidos de forma interrelacionada, o que requer, portanto, que se descarte as abordagens fragmentadas, que separam o que é da esfera natural e da esfera social. Como decorrência, impõe-se então que se passe a adotar uma concepção de conhecimento inter/transdisciplinar. A segunda pertinência é referente à orientação que busca construir a formação em diálogo com os envolvidos no processo, e dessa forma valoriza a ideia de formação autogerida. A terceira pertinência, a qual guarda relação com a segunda, concerne ao fato de se tomar em conta os contextos de trabalho docente também como lócus de formação, o que se apresenta como algo de relevância significativa, pois os contextos de trabalho constituem espaços onde, fundamentalmente, as identidades profissionais são construídas. A quarta pertinência tem a sua origem no modo como se concebe a gestão/desenvolvimento da formação, isto é, buscando-se parcerias com universidades, ONGs e a sociedade civil em geral, o que permite que as demandas de formação para atuação em EA sejam apreciadas de forma dialógica e mais próxima à realidade.

Isto posto, ou seja, tendo sido ressaltadas as pertinências das políticas de formação de educadores ambientais, cabe analisar alguns dos seus aspectos abstrusos.

O primeiro deles incide sobre uma determinada ininteligibilidade de algumas formulações, a exemplo de quando se aborda a necessidade de formar o educador ambiental a partir do 'desenvolvimento de competências'. Por vezes, os enfoques a esse respeito se sobrepõem, repetem-se, em construções retóricas genéricas, sem que se clarifique, de forma objetiva, o que significa isso do ponto de vista da operacionalização concreta.

Outro aspecto abstruso concerne à referência aos contextos não formais como espaços a serem valorizados para o desenvolvido de formação de educadores ambientais, sem que, contudo, se clarifique o que se está a entender por contextos não formais, visto que, nesta esfera, tem predominado constantes desencontros (extremos) de compreensão acerca do que são os espaços educativos não formais, havendo até mesmo quem, mais recentemente, esteja a propor a superação dessa terminologia, o seu não uso ${ }^{6}$.

De certo modo, o que acabamos de assinalar também vale para a utilização do termo desenvolvimento sustentável - o que vem a ser o terceiro aspecto abstruso. $\mathrm{O}$ mencionado termo, aliás, cada vez mais tem se revelado bastante controverso, "abarcando tudo" e sendo referido indistintamente por pessoas e segmentos de diferentes quadrantes ideológicos, de modo que, sem maiores clarificações a seu respeito, ele tem se transformado numa expressão sem significação, servindo fortemente como peça de 
dissimulação no jogo retórico que envolve as relações de poder na arena políticoeconômica e social.

$\mathrm{O}$ quarto aspecto abstruso relaciona-se ao modo como as questões de natureza cognitiva estão tratadas - ou melhor, não estão - nas políticas de formação de educadores ambientais. Há uma subpresença da dimensão cognitiva nas abordagens, prevalecendo enfoques mais gerais, guiados por petições de princípio ancoradas na dimensão política. Tal ancoragem só terá relevância na medida em que não seja revestida por generalidades, bem como também não despreze os fatores de ordem cognitiva, os quais têm um lugar central nas definições e encaminhamentos em torno do processo de ensino-aprendizagem. Se não for assim, torna-se algo bastante problemático.

Last but not least, um aspecto abstruso refere-se a uma definição mais precisa em torno da concepção de educação ambiental com a qual se opera, explicitando os elementos que lhe dão conteúdo e forma. Há aqui, nas políticas brasileiras voltadas à formação de educadores ambientais, um misto entre indefinição e excesso de ecletismo, ora caindo-se num indefinido ativismo pedagógico, ora abonando, sem maiores considerações, perspectivas controversas, e até mesmo alimentadas pelo marketing "politicamente correto" do mercado, a exemplo da apologia a determinadas versões do "desenvolvimento sustentável', que não passam de peças de propaganda empresarial.

\section{Meio ambiente, políticas e educação no Brasil: condicionamentos, limites e desafios}

Uma das características fundamentais da análise objetiva da realidade social é a transposição do que, aparentemente, se apresenta como dado e inquestionável. As inferências que podem ser tiradas da análise de determinada situação empírica, desde que seja uma análise que problematize o objeto em foco, terá, portanto, que captar as abstrações que revestem os supostos "dados da realidade".

$\mathrm{Se}$, anteriormente, colocamos em evidencia e discutimos as perspectivas das políticas brasileiras de educação ambiental, agora realçaremos algumas inferências que, indo além da aparência do que "está dado", emergem como resultado da abordagem empírico-analítica do objeto enfocado.

Inferimos, por exemplo, que as políticas brasileiras de educação ambiental, independentemente da mudança de governo que ocorreu no país em 2002, com a eleição do ex-Presidente Luís Inácio Lula da Silva, não sofreram, em termos de matriz programática, alterações substancias em sua construção. A esse respeito, é ilustrativo que, no básico, a PNEA tenha sido mantida conforme os parâmetros da lei aprovada em 1999, assim como o PRONEA, instituído em 1994, tenha passado por ajustes em 2004, mas sem ter sido submetido a alterações fundamentais de escopo. Há, parece, mais de uma hipótese a ser considerada para explicar essa situação. É possível, talvez, que as políticas de educação ambiental não tenham sofrido alterações substanciais por a sua construção, seja em um governo ou em outro, se ter dado com a participação dos mesmos agentes da sociedade civil (ambientalistas, movimentos sociais, especialistas do mundo acadêmico, etc.), em um processo que teve como ponto impulsionador a Conferência das Nações Unidas sobre o meio ambiente, realizada no Rio de Janeiro em 1992, a chamada ECO 92. Deve-se considerar também a possibilidade de essa continuidade decorrer de uma determinada sintonia programática, na referida área, do governo que ascendeu ao poder em 2002 em relação às políticas do governo anterior.

Inferimos também que, não obstante o volume de discussões oficiais promovidas e as publicações realizadas (muitas tornando públicas as discussões feitas), não se tem conseguido produzir materiais com aderência pedagógica. Isto por duas razões, quais 
sejam: primeira, ora não se consegue fazer a transposição didática necessária para que os conhecimentos científicos tenham tradução prática no cotidiano educativo; isto é, não se consegue tornar disponível/inteligível o conhecimento científico sobre as questões ambientais em uma linguagem pedagogicamente acessível para a realização das atividades de EA. Quanto à segunda razão, refere-se ao fato de que, por vezes, cai-se na repetição de chavões pedagógicos, com sobreposições retóricas e repetições desprovidas de conteúdo significativo. Os efeitos tanto da primeira quanto da segunda razão sobre as elaborações em torno, por exemplo, da formação de educadores ambientais constituem-se em empecilhos para a sua operacionalização.

Inferimos, ainda, que, como consequência do que estivemos a realçar, as políticas brasileiras de educação ambiental têm sido marcadas por avanços e recuos, ora assumindo uma agenda a altura dos desafios contemporâneos; ora fazendo concessões à ideologia produtivista do desenvolvimento a qualquer custo, sobretudo quando tais políticas se mantêm omissas diante das versões ideológicas do chamado desenvolvimento sustentável, que, paradoxalmente, promete sustentabilidade em sociedades insustentáveis, e não se dispõe a mudar as bases dessas sociedades.

As políticas brasileiras de educação ambiental, enfim, refletem o contexto material e sócio-histórico em que elas são formuladas, onde as relações de poder estão em jogo, verificando-se que, nessa atmosfera, as políticas públicas são a expressão da síntese aglutinadora dos diferentes interesses em disputa.

Dessa forma, é necessário assinalar que, dos anos 1990 ao presente, o Brasil tem vivenciado agendas macropolíticas que repercutem sobre as políticas específicas de educação ambiental.

A década de 1990 - deposto o Presidente Fernando Collor, feita a transição do governo Itamar Franco para Fernando Henrique Cardoso - foi fundamentalmente uma década de ortodoxia liberal no Brasil, apostando-se na lógica do mercado como dispositivo regulador da sociedade, significando isso, por exemplo, não só a redução da presença do Estado na economia e a abertura desta ao capital externo, mas também o decréscimo do papel estatal como agente que pensa planos para a Nação, a diminuição do alcance dos serviços públicos e a valorização de um tipo de sociabilidade assente mais na concorrência do que na cooperação, de modo que a dinâmica da vida social tem como horizonte as aspirações individuais, ao invés dos projetos coletivos.

Foi nesse ambiente que as políticas de educação ambiental, no país, foram pensadas nos anos 1990. Não chega a surpreender, portanto, que as formulações governamentais na área tenham estado tão susceptíveis à influência de organizações internacionais, como a UNESCO, sendo inclusive no curso das posições desta agência que iniciativas oficiais foram instituídas no Brasil. Aliás, conforme a densa literatura sobre este tema, está consistentemente demonstrado que, na sequência das conferências internacionais de educação na década de 1990, as reformas que se seguiram no Brasil estiveram sob a influência externa, tanto de organizações como a UNESCO e o Banco Mundial, como de experiências que foram adotadas em outros países, como ocorreu no caso da influência da reforma espanhola sobre os Parâmetros Curriculares Nacionais (PCNs), tendo-se inclusive que César Coll, um dos coordenadores dessa, foi consultor do MEC na elaboração dos PCNs, não obstante os severos questionamentos a Coll, por seu 'confuso ecletismo teórico'. Conforme afirmou Duarte (2004, p. 58), “o princípio metodológico básico de César Coll (...) nada mais é do que a liberdade que esse autor concede a si mesmo, de extrair das várias teorias o que lhe pareça mais útil, jogando fora o resto da teoria e interpretando como bem lhe aprouver a parte que foi recortada". 
Nesse 'quadro eclético de confusão teórica', foram pensadas, no governo FHC, ações para a educação ambiental, a exemplo da iniciativa, nos PCNs, que a define como tema transversal (BRASIL, 1997).

Sob determinados aspectos, parece que, na administração Fernando Henrique, a questão do meio ambiente - e com ela a educação ambiental - foi utilizada como verniz para lustrar no exterior a sua imagem como estadista sintonizado com uma problemática central na contemporaneidade. Assim, ao menos formalmente, buscou-se aproximação com as diretrizes das conferências sobre meio ambiente, até mesmo por o Brasil ter sido anfitrião da conferência de 1992, a Eco 92. Essa imagem de "moderno" no exterior, contudo, era contrastante com o perfil e o estilo dos seus ministros do meio ambiente, assim como com as efetivas ações adotadas. Basicamente, a pasta do meio ambiente foi conduzida por Gustavo Krause (01 de janeiro de 1995 a 01 de janeiro de 1999), político formado nos estofos da ditadura militar no nordeste do país, e José Sarney Filho (01 de janeiro de 1999 a 05 de março de 2002), oriundo de uma das mais longevas oligarquias do país, comandada diretamente do Maranhão pelo ex-Presidente José Sarney, de quem o exministro é filho. Completou o período FHC, no Ministério do Meio Ambiente, o engenheiro José Carlos Carvalho (05 de março de 2002 a 31 de dezembro de 2002).

No conjunto da gestão da questão ambiental, no período, some-se a essa configuração administrativa no Ministério do Meio Ambiente o fato de ter sido titular do Ministério da Educação, durante todo o governo Fernando Henrique Cardoso, Paulo Renato de Souza, economista e ex-funcionário do Banco Interamericano de Desenvolvimento, com estreitas ligações, nessa condição, com a pauta político-ideológica das organizações internacionais.

Com o fim do governo FHC e o início do governo Lula, é de se notar, em primeiro plano, um fenômeno de dupla face aparentemente contraditório: mudança e continuidade. Mudança no âmbito político, buscando-se um novo pacto entre forças sociais, no sentido de promover um 'capitalismo social', mais inclusivo, com forte aposta na robustez do mercado interno e na ampliação do consumo. Quanto à continuidade, ela se traduziu na manutenção dos fundamentos da política econômica do governo Fernando Henrique, a exemplo do chamado tripé representado pelo regime de metas de inflação, câmbio flutuante e superávit primário.

Daí resultou o chamado neodesenvolvimentismo, expressão-síntese da agenda dos governos conduzidos pelo PT. Como assinala Sampaio Jr. (2012, p. 679):

A modesta retomada do crescimento econômico, após quase três décadas de estagnação, a lenta recuperação do poder aquisitivo do salário após décadas de arrocho, a ligeira melhoria na distribuição pessoal da renda, o boom de consumo financiado pelo endividamento das famílias e a aparente resiliência do Brasil perante a crise econômica mundial dão um lastro mínimo de realidade à fantasiosa falácia de que, finalmente, o Brasil estaria vivendo um ciclo de desenvolvimento. O chamado neodesenvolvimentismo seria, assim, uma expressão teórica desse novo tempo.

O denominador comum do neodesenvolvimentismo incide sobre a busca de uma terceira via entre o neoliberalismo e os problemas do velho desenvolvimentismo, que emergiu na CEPAL tendo Celso Furtado como um dos seus principais representantes. Do neoliberalismo, recusa-se a cumplicidade com o rentismo, e do antigo desenvolvimentismo rejeita-se o 'nacionalismo anacrônico', a 'complacência com a inflação' e o 'populismo fiscal'. De acordo com Sampaio Júnior (IBIDEM, p. 679), em síntese, pode-se dizer que: 
O desafio do neodesenvolvimentismo consiste, portanto, em conciliar os aspectos "positivos" do neoliberalismo - compromisso incondicional com a estabilidade da moeda, austeridade fiscal, busca de competitividade internacional, ausência de qualquer tipo de discriminação contra o capital internacional - com os aspectos "positivos" do velho desenvolvimentismo - comprometimento com o crescimento econômico, industrialização, papel regulador do Estado, sensibilidade social.

A perspectiva neodesenvolvimentista carece de maiores formulações, que the assegurem maior sustentação. As vagas elaborações a seu respeito são débeis no que se refere ao modo de combinação dos referidos aspectos positivos e negativos. Elas giram em torno dos instrumentos que devem ser mobilizados pela política econômica para superar os obstáculos ao crescimento e conciliar as exigências do equilíbrio macroeconômico com os objetivos da política industrial e as necessidades orçamentárias da política social. Não é colocada em causa a dupla articulação dependência externa e segregação social. Portanto, não são considerados os efeitos da agenda/ordem global sobre a economia brasileira.

O propósito de depurar o 'lado negativo' e condensar os 'aspectos positivos' dos dois polos assume uma forma de 'hibridismo acrítico' que se afirma menos pela originalidade de sua interpretação e mais pela contraposição de suas posições alternativas aos dogmas da ortodoxia. Dessa forma, assevera Sampaio Jr. (IBIDEM, p. 680):

Toda a reflexão neodesenvolvimentista enquadra-se perfeitamente na pauta neoliberal. Na prática, a terceira via torna-se uma espécie de visão ultra light da estratégia de ajuste da economia brasileira aos imperativos do capital financeiro. O diferencial do neodesenvolvimentismo se resume ao esforço de atenuar os efeitos mais deletérios da ordem global sobre o crescimento, o parque industrial nacional e a desigualdade social.

Por outro lado, o método de ocultação sistemática do negativo e de exaltação acrítica do crescimento e da modernização dos padrões de consumo transforma vício em virtude. A relação entre desenvolvimento e barbárie social, uma marca do nosso tempo, "que se manifesta com virulência redobrada nas economias periféricas, converte-se assim, por um passe de mágica, no seu contrário: o desenvolvimento capitalista virtuoso capaz de conciliar crescimento com equidade (IBIDEM, p. 681).

É nesse contexto, de macro orientação político-econômica, que as ações em torno da educação ambiental têm sido desenvolvidas nos governos conduzidos pelo PT, sobretudo nos dois governos Lula e no primeiro governo Dilma. Uma das principais medidas desse período teve lugar logo no início do primeiro governo Lula, quando, contando com o empenho da então Ministra Marina Silva, foi instituído o Órgão Gestor da Política Nacional de Educação Ambiental, alinhando o Ministério da Educação e o Ministério do Meio Ambiente, numa articulação em que o primeiro era representado pela Coordenação Geral de Educação Ambiental (CGEA) e o segundo pela Diretoria de Educação Ambiental (DEA).

Analiticamente, apreende-se um certo grau de ambivalência em relação às ações de educação ambiental que passam a ser adotadas, ambivalência decorrente, ao que parece, das próprias contradições do neodesenvolvimentismo e também da linha de continuidade entre a matriz que norteou a educação ambiental no governo FHC e a que serviu de base às iniciativas nas gestões da coalizão petista. Até como o próprio tempo veio a revelar, em campanha eleitoral recente, a então Ministra Marina Silva conservava uma determinada sintonia com as políticas do governo FHC para a área ambiental (e não só para esta área), e 
desse modo, tanto na administração FHC como na gestão petista, esteve desempenhando um papel central orientações de organizações internacionais como a UNESCO - aliás, é de se assinalar a facilidade com a qual a ex-Ministra Marina Silva transita internacionalmente entre os órgãos/setores que tratam da questão ambiental.

Ao mesmo tempo, sob o amparo do peso simbólico da pessoa da Ministra, por sua história, a partir do Ministério do Meio Ambiente e com o apoio de ambientalistas, procurou-se intensificar uma agenda que contraditava frontalmente com as perspectivas do neodesenvolvimentismo. Pode ser referido neste sentido, por exemplo, os desencontros em torno do Plano Amazônia Sustentável, bem como as divergências em relação às licenças ambientais, sendo a Ministra acusada de atrasar a concessão destas para as obras de infraestrutura e assim ser empecilho a 'marcha do desenvolvimento'. O agravamento das discordâncias levou a Ministra a entregar o cargo, sendo substituída por Carlos Minc.

Seja como for, o que importa reter é que, independente de 'diferenças de encaminhamento' e mesmo de percepção em determinados casos, a matriz básica da agenda ambiental do governo brasileiro, desde a administração FHC, é condicionada pelas orientações de organizações como a UNESCO, com as suas proclamações vazias em torno do chamado desenvolvimento sustentável.

Com pequenas diferenças de tematização, as concepções de educação ambiental têm sido categorizadas como a educação ambiental para a mudança de comportamentos ambientalmente incorretos; a educação ambiental centrada na transmissão de conhecimentos técnicos e científicos sobre os processos naturais; a educação ambiental como um processo de apropriação crítica de conhecimentos, atitudes e valores (TOZONIREIS, 2007) - sendo as duas primeiras concepções consideradas acríticas, por não irem às raízes dos problemas ambientais e da crise ecológica que o mundo vive, pois isto requer que sejam levadas em conta as questões político-econômicas decorrentes do modo capitalista de produção e a sua necessidade permanente de acumulação em escala ampliada. O que faz com que ele avance destrutivamente sobre o meio ambiente e promova o consumismo desenfreado, o que torna, portanto, ilusório imaginar sociedades sustentáveis sem transformações estruturais.

A posição com a qual a UNESCO (1985), historicamente, tem operado oscila entre as duas primeiras concepções referidas, ora recorrendo de forma absoluta às prescrições da tecnocracia (sem ter em atenção as perspectivas das comunidades locais), ora limitando as responsabilidades pelos problemas ambientais aos comportamentos individuais, como se houvesse equivalência, por exemplo, no grau de responsabilidade de indivíduos e empresas na poluição do meio ambiente.

Pela amplitude do território brasileiro, pela dimensão da sua biodiversidade, pelas particularidades da região amazônica, etc., o Brasil tem diante de si desafios ambientais que, do ponto de vista da educação, requerem mais do que prescrições exógenas de organizações internacionais, as quais, historicamente, têm balizado as políticas educativas do país.

\section{À guisa de conclusão}

Neste trabalho, tivemos como propósito, a partir de fontes primárias e da bibliografia especializada, desenvolver uma análise das políticas de educação ambiental no Brasil, adotando um enfoque que busca tratar os seus contextos sob uma abordagem que os apreende em sua longa interconexão histórica, bem como considerando os fatores que lhes condicionam. Nesse sentido, começamos por evidenciar um panorama histórico das políticas brasileiras de educação ambiental, passando, em seguida, a realçar os percursos e 
perspectivas das propostas de formação de educadores ambientais, para então, posteriormente, fazermos um exercício de problematização em torno da temática ambiental e das políticas educacionais brasileiras pensadas em função dela.

Muito embora por caminhos diferentes, os governos brasileiros dos últimos vinte anos (administrações Lula, FHC e Dilma) desenvolveram formulações em torno da educação ambiental que conservam graus de semelhança em seus pressupostos básicos. Não obstante os confrontos retóricos entre o PT e o PSDB tendam a acentuar divergências em relação às suas políticas, o fato é que as iniciativas de ambos, voltadas à educação ambiental, mantêm um considerável nível de sintonia, na medida em que, por exemplo, internacionalmente, foram elaboradas sob o condicionamento das mesmas orientações.

Uma das consequências mais diretas dessa sintonia é relativa ao modo como a noção (ou, caso se queira, o conceito) de desenvolvimento sustentável tem sido assimilado e o lugar central que ele tem ocupado na agenda das políticas brasileiras. Tem sido assimilado de forma acrítica, apresentando-se como autoexplicativo (dispensando, portanto, discussão a seu respeito), mas trata-se de uma expressão com significativas inconsistências do ponto de vista do conteúdo, seja porque não consubstancia com nitidez e coerência lógico-argumentativa as suas premissas, seja porque o que anuncia retoricamente (sustentabilidade) é algo incompatível com os marcos societais nos quais a tese do desenvolvimento sustentável opera, quais sejam, os que limitam a vida à produção e circulação de mercadorias, sob a lógica da reprodução ampliada do capital e a indução do consumismo. Isto é, por outras palavras, o desenvolvimento sustentável promete sustentabilidade em sociedades que, para existirem, nutrem a insustentabilidade ambiental, tanto do ponto de vista da produção como do consumo. Assim sendo, o discurso do desenvolvimento sustentável revela-se como ideologia, no sentido clássico de mascaramento da realidade.

Dessa forma, pensar uma agenda alternativa de educação ambiental no Brasil requer tomar em conta, portanto, as lições das políticas historicamente adotadas no país, e desde logo relativizar as macroorientações das organizações internacionais que, com a ação das suas burocracias, o que fazem do ponto de vista ambiental é reproduzir e repor em outros patamares os problemas que, em tese, pretendem combater. Trata-se de uma agenda, enfim, que inverta os sinais e coloque de parte a petição de "princípios" (meramente retóricos) em torno do desenvolvimento sustentável e assuma como imperativo uma dupla perspectiva: superar o mascaramento ideológico em volta da temática ambiental, que, como é próprio da ideologia, apresenta de forma inversa, assim como perversa, partes do real; e pugnar por um outro desenvolvimento que, mesmo que surja no âmbito econômico, deságue no plano social e adquira uma dimensão política mediante a igualdade que realiza, representando a ampliação da liberdade em todas as esferas da vida.

\section{Referências}

BRASIL (2004). Programa Nacional de Educação Ambiental (PRONEA). Disponível em: < http://www.mma.gov.br/estruturas/educamb/_arquivos/pronea_3.pdf>. Acesso em: 25 de maio de 2015.

BARSIL (2002). Decreto $\mathrm{n}^{\circ} 4.281 / 2002$ - Regulamenta a Lei $\mathrm{n}^{\circ} 9.759$ e dá outras providências. Disponível em: http://www.planalto.gov.br/ccivil_03/decreto/2002/d4281.htm>. Acesso em: 26 de maio de 2015. 
BRASIL (1997). Parâmetros Curriculares Nacionais - Meio Ambiente e Saúde, vol. 09. Disponível em: <http://portal.mec.gov.br/seb/arquivos/pdf/livro091.pdf >. Acesso em: 23 de maio de 2015.

BRASIL (1999). Lei no 9.795/99 - Dispõe a Educação Ambiental, institui a Política Nacional de Educação Ambiental e dá outras providências. Disponível em: < http://www.planalto.gov.br/ccivil_03/leis/19795.htm>. Acesso em: 26 de maio de 2015.

BRASIL (1988). Constituição da República Federativa do Brasil. Disponível em: < http://www.planalto.gov.br/ccivil_03/constituicao/constituicao.htm>. Acesso em $26 \mathrm{de}$ maio de 2015.

BRASIL (1981). Lei no 9.398/81 - Dispõe sobre a Política Nacional de Meio Ambiente, seus fins e mecanismos de formulação e aplicação, e dá outras providências. Disponível em: < http://www.planalto.gov.br/ccivil_03/leis/16938.htm> . Acesso em: 26 de maio de 2015.

DUARTE, Newton (2004). Vigotski e o "aprender a aprender": crítica às apropriações neoliberais e pós-modernas da teoria Vigotskiana. Campinas, SP: Autores Associados.

SAMPAIO JR., Plínio de A. (2012). Desenvolvimento e neodesenvolvimento: tragédia e farsa, in Serviço Social \& Sociedade, São Paulo, no 112, p. 672-678, out./dez. 2012.

SAVIANI, Demerval (1998). O debate teórico e metodológico no campo da história e sua importância para a pesquisa educacional, in: SAVIANI, Demerval; LOMBARDI, José C.; SANFELICE, José L. (Orgs.). História e educação: o debate teórico-metodológico atual. Campinas-SP: Autores Associados.

SOUZA NETO, João Clemente de; SILVA, Roberto da; MOURA, Rogério Adolfo (Orgs.). Pedagogia social. São Paulo: Expressão e Arte, 2009.

TOZONI-REIS, Marília Freitas de C. (2007). Contribuições para uma pedagogia crítica da Educação Ambiental: reflexões teóricas, in: LOUREIRO, Carlos Frederico B. (Org.). A questão ambiental no pensamento crítico: natureza, trabalho e educação. Rio de Janeiro: QUARTET, p. 177-219.

UNESCO (1985). Interdisciplinary approaches in environmental education. Paris: UNESCO/Division Science, Technical and Environmental Education.

VIANNA, Lucila P (2002). Formação em meio ambiente para o ensino formal: uma proposta de formação continuada em serviço para as séries finais do ensino fundamental, in MARFAN, Marilda A. (Org.). Congresso Brasileiro de Qualidade na Educação: Formação de professores. Vol II. Brasília: MEC, SEEF. 


\section{Notas}

${ }^{1}$ Este trabalho foi produzido no âmbito de um projeto apoiado pelo $\mathrm{CNPq}$, sob os auspícios do Edital $58 / 2010$.

${ }^{2}$ Seis anos antes, em 1967, havia sido criado o Instituto Brasileiro de Desenvolvimento Florestal (IBDF). Contudo, a atenção à questão ambiental em si, no Instituto, era mínima, visto que ele estava mais voltado à gestão das florestas para o desenvolvimento agrícola. Tanto assim o era que estava vinculado ao Ministério da Agricultura.

${ }^{3}$ A Lei criou o Sistema Nacional de Meio Ambiente (SISNAMA) e o Conselho Nacional do Meio Ambiente (CONAMA).

${ }^{4}$ A criação do IBAMA resultou da fusão dos seguintes órgãos: Instituto Brasileiro de Desenvolvimento Florestal (IBDF), Superintendência de Pesca (SUDEPE), Superintendência da Borracha (SUDHEVEA) e Secretaria do Meio Ambiente (SEMA).

${ }^{5}$ Lucila Pinsard Vianna, conforme escreveu numa publicação do MEC sobre o tema (VIANNA, 2002).

${ }^{6}$ A esse respeito, ver Souza Neto et. al. (2009), onde se propõe a mudança conceitual de educação não formal para pedagogia social.

Recebido: maio-15 Aprovado: julho-15 